\title{
Screening of Bacteria in the Biodegradation of Linear Alkyl Benzene Sulfonate (LBAS) From Car Wash Waste Water in Tehran (Iran)
}

\section{Vida Fakhar}

Research Network

Hanieh Ghasemi

Research Network

Mohsen Naghmachi

Yasuj University of Medical Sciences

Javid Amini

Research Network

Farzane Amirmahani

Research Network

Marzieh Danaei ( $\nabla$ danagenepk@gmail.com )

Research Network https://orcid.org/0000-0002-2095-5838

\section{Research Article}

Keywords: Anionic biosurfactants, Biodegradation, Bacillus licheniformis, Car wash effluent

Posted Date: September 17th, 2021

DOl: https://doi.org/10.21203/rs.3.rs-841481/v1

License: (9) (i) This work is licensed under a Creative Commons Attribution 4.0 International License. Read Full License 


\section{Abstract}

Linear alkyl benzene sulfonate (LABS) is a substance used as a surfactant in anionic detergents. Today, it is the most widely used surfactant in detergent products after soap. The aim of this study was to screen effective isolates for the degradation of LABS from car wash effluents in Tehran (Iran).

In this study, 10 effluent samples were randomly collected from car washes in Tehran (Iran). Isolation of mesophilic aerobic bacteria was performed by direct and pre-enrichment culture techniques.

Biodegradation of sodium dodecyl sulfonate by isolates and turbidity was investigated by methylene blue active substance (MBAS) method, and the superior strain was identified by molecular method (Polymerase Chain Reaction, PCR), which approximately $86 \%$ of the material was degrade by the bacterial isolate, and the isolate was identified as Bacillus licheniformis.

The results of MBAS method showed that the rate of LBAS degradation by bacteria was $86 \%$, which indicates the high power of this bacterium to degrade LABS from sewage systems (car wash effluents). It was also shown that the concentration of LABS during 8 days of biodegradation period by this bacterium decreased from $80 \%$, which indicates a significant decrease in LABS by Bacillus licheniformis.

According to our results, Bacillus licheniformis can be used to dagrade LABS and its degradation in wastewater treatment systems of car wash effluents whose effluents are based on alkyl benzene sulfonates.

\section{Introduction}

Linear alkyl benzene sulfonate (LBAS) is one of the largest group of anionic surfactants used in various detergents and with $97-99 \%$ decomposition is considered as a biodegradable surfactant(Steber and Berger 1995). It is the most widely used household detergent after soap and is used in more than 100 countries as a raw material for the production of household surfactants such as washing powders, dishwashing liquids and other cleaners(Yangxin et al. 2008). The LABS molecule has three building blocks: a hydrocarbon chain with a carbon content of between 14 and 10, a benzene ring connected to a hydrocarbon chain, and a Sulfonate group, which is attached to the benzene ring(Takeda et al. 2019). The high levels of LABS, found in different habitats (including watersheds, wastewater treatment systems, sludges filling the ground and added to the soil, river water, river sediments, soil surface, groundwater, and springs), were measured by HPLC (High Performance Liquid Chromatography) and confirmed by GC (Gas Chromatography) and MBAS (Methylene Blue Active Substance)(Rapaport and Eckhoff 1990).

LABS has been shown to decompose by about $97-99 \%$ in wastewater treatment systems with suitable activated sludge, ie sludge containing LABS degrading bacteria, which is the result of two simultaneous biodegradation, adsorption, and precipitation(Kahl et al. 2018). The adsorption and precipitation process accounts for approximately $30-35 \%$ (rarely 10 to $20 \%$ ) of the LABS degradation operation. In addition, in higher hardness waters, the LABS deposited in the primary sedimentation tank is higher and as a result, the amount of LABS transferred to the biological treatment will be less and less treatment will be 
performed(Ghebremichael 2004). On the other hand, the sediments in the primary sedimentation tank are transferred to the process of anaerobic digestion or anaerobic decomposition and enter the soil if the sludge spreads on the ground. A previous research has shown the toxicity of branched-chain acyl benzene sulfonates to bacteria and protozoa in wastewater treatment processes. According to Manganelli, concentrations of $62.5 .5 \mathrm{mg} / \mathrm{dm} 3$ and $12.5 .5 \mathrm{mg} / \mathrm{dm} 3$ of branched alkyl benzene inhibit the growth of E.coil and Pseudomonas species. In anaerobic digestion of sewage sludge, a concentration of $1.5 \%$ (dry weight $\mathrm{w} / \mathrm{w}$ ) can stop the production of methane by methanogenic bacteria (Wang et al. 2009).

The foaming phenomenon due to the presence of surfactants can cause the transfer of microorganisms in the wastewater treatment process and eliminate the active biomass in the upper layer (Wu et al. 2020). Studies have shown that replacing the linear alkyl benzene sulfonates with their branched type can reduce foam production (Suresh and Abraham 2019). The diversity of microorganisms with the potential to decompose xenobiotic compounds and produce new metabolites has expanded in recent studies (Singer et al. 2003). Due to the existence of different types of detergents in the market and their excessive consumption and the importance of environmental protection, today human attention is focused on methods of degrading these pollutants from the environment. Due to the fact that physical, chemical and physicochemical degradation methods have low efficiency and are also costly, so today the attention of researchers is focused on using the ability of microorganisms to degrade this type of contaminant. Therefore, in this study, we try to evaluate LABS analysis, which is widely used in detergents, by microorganisms obtained in the in vitro screening stage, and the superior strains to optimize the analysis conditions are studied in more detail.

\section{Material And Methods}

Sample collection and preparation

10 samples of effluents were randomly collected from different car washes in Tehran (light-heavy machine) and transferred to the laboratory under sterile conditions for microbial analysis. Then, to prepare the dilution, $1 \mathrm{~mL}$ of the sample was transferred to $9 \mathrm{~mL}$ of physiological saline, and completely mixed, and this operation was performed up to $10^{-6}$ dilution and from the prepared dilutions, the media were inoculated.

Isolation of aerobic mesophilic bacteria

From the prepared dilutions, surface culture was performed directly on the surface of nutrient agar media (direct culture) and all inoculated media were incubated for $30-72$ hours at $30^{\circ} \mathrm{C}$. Then, based on the appearance characteristics of growth bacteria were selected by neddle, and cultured on the surface of TSA (Tryptic Soy Agar), TSB (Tryptic Soy Broth), and Sabouraud dextrose agar (SDA), containing chloramphenicol. 
Determination of biodegradation of alkyl benzene sulfonates in a minimal salt medium (MSM) containing LABS

This test method is a criterion for measuring the environmental compatibility of sulfonates used as surfactants by measuring the biodegradability of LABS. In this test, the microorganisms are inoculated into a container containing the MSM and the surfactant being tested. After two stages of compatibility, biodegradability is determined by measuring the reduction of surfactant during the experiment. If the reduction of surfactant during the test period is more than $80 \%$, it indicates the degradation of surfactant by bacteria. Moreover, the reference surfactant material was Dodecyl hydrogen sulfate sodium ((MERCK) NO.2969). To this aim, $500 \mathrm{~mL}$ of the MSM was poured, and one of them was identified as a control stock containing $10 \mathrm{~mL}$ of LABS surfactant from LABS storage solution and was free of bacteria. In other stock, surfactant was added to the MSM in addition to each of the bacteria in a ratio of $1 \mathrm{~mL}$ to $100 \mathrm{~mL}$. Thus, stocks containing MSM medium, surfactant and inoculated bacteria were prepared for degradability test.

Before starting the biodegradability test, two initial compatibility steps must be performed for 72 hours in the mentioned stock. After the initial adjustment step, $500 \mathrm{~mL}$ of these stocks were added to the stocks containing fresh medium plus LABS, at a rate of $10 \mathrm{~mL}$ of storage solution and kept for 72 hours, for secondary compatibility. At the beginning of the degradability test (immediately after inoculation and mixing the contents of the stock) and also on the eighth day, samples were taken and the amount of surfactant in these samples was measured by MBAS method and the results were recorded.

Surfactant measurement test by MBAS method

The basis of this test is to measure the amount of surfactant by complexion with methylene blue in the chloroform phase. This method is able to measure the amount of LABS from 0.05 to $1.5 \mathrm{mg} /$ I per 100 $\mathrm{mL}$ of sample. To measure the amount of LABS in the sample, certain amounts of LABS storage solution of $0,0.1,0.2,0.3$ and $0.5 \mathrm{ml}$ per sample were taken first, and a few drops of phenolphthalein and a sufficient amount of $\mathrm{NaOH}$ were taken. Added to create a pink color. Then, dilute sulfuric acid was added drop wise to color the solution. Then, $25 \mathrm{~mL}$ of methylene blue was added and after mixing, $25 \mathrm{~mL}$ of chloroform was added to the separating funnel. After 30 seconds, when the two phases were separated, the chloroform layer was transferred to another $250 \mathrm{ml}$ separating funnel and $25 \mathrm{ml}$ of chloroform was added again. In the second step, $50 \mathrm{ml}$ of phosphate washing solution was added, and after 1 minute of settling, the chloroform layer was extracted. Washing with chloroform was continued until the sample volume reached $100 \mathrm{~mL}$.

Then the prepared samples were stored and a calibration diagram for different values was drawn with a spectrophotometer at $650 \mathrm{~nm}$.

$\mathrm{PH}$ measurement 
Using a pH meter, the solution containing (LABS) and bacteria was adjusted to $\mathrm{pHs}$ of 5,7 and 9 using 1 Normal hydrochloric acid $(\mathrm{HCl})$, and Sodium Hydroxide $(\mathrm{NaOH})$.

Measurement of LABS concentration based on spectrophotometry analysis

To measure the optical absorption to obtain the concentration of LABS by MBAS method on day zero, the device with a wavelength of $650 \mathrm{~nm}$ was set to 0 absorption. Then some of the solutions containing chloroform and methylene blue together with concentrations of LABS were transferred into the cell of the spectrophotometer and with a wavelength of $650 \mathrm{~nm}$ the absorption rate of each of them was read by the device. The results of light absorption and calculation of LABS concentration for samples containing bacteria in $\mathrm{mg} / \mathrm{L}$ on day 0 were recorded.

To measure the amount of light absorption to calculate the concentration of LABS, after passing the biodegradation period by MBAS method on the eighth day with standard solution No. 1, the concentration of LABS was $0 \mathrm{mg} / \mathrm{I}$, the device with a wavelength of $650 \mathrm{~nm}$ was set to 0 absorption. Then, some of the contents of LABS-containing samples were poured into the cells of the spectrophotometer for bacteria, respectively, and the absorption of each of them was read with a wavelength of $650 \mathrm{~nm}$. Then, from the calibration curve, the concentration of LABS in $\mathrm{mg} / \mathrm{I}$ was calculated from the light absorption.

The percentage of LABS decomposed by Bacillus licheniformis bacterium was calculated by reducing the concentration of surfactant tested by MBAS method on day 0 and after day 8 using the following formula:

LABS concentration $(\%)=\left(\left(S_{-}\right.\right.$0-B_0 $)-($S_X-B_x $\left.)\right) /\left(S_{-} 0-B \_0\right) \times 100$

Where $S_{-} 0$ and $S_{-} \times$are the amount of surfactant on day 0 (start day) and day $x$, and B_0 and B_x are the amount of surfactant on day 0 and day $x$, expressed in $\mathrm{mg} / \mathrm{L}$. The test results were calculated as the mean of the decomposed percentage on the eighth day, and then displayed as the mean.

Macroscopic, microscopic and biochemical analyses

Regarding the identification of the main bacterial isolate in LABS degradation, macroscopic (colony characteristics), microscopy (gram staining) and biochemical (lecithinase, citrate, and growth in anaerobic conditions) tests were done.

Molecular analysis

In order to confirm the isolates, DNA extraction was performed by CTAB method, as described previously(Cota-Sánchez et al. 2006). Then, the quantity and quality of the isolated DNA was determined using spectrophotometry and gel electrophoresis. After that, 16s rRNA gene was amplified by Polymerase Chain Reaction (PCR) using Master Mix (Sinaclone, Iran), in a BioRad thermal cycler system according to the following program: One step Initial at $5^{\circ} \mathrm{C}$ for 5 minutes, 35 cycles at $95^{\circ} \mathrm{C}$ for 1 minute, $57^{\circ} \mathrm{C}$ for 1 minute, $75^{\circ} \mathrm{C}$ for 75 seconds and a final expansion step at $10^{\circ} \mathrm{C}$ for 10 minutes. In this study, universal 
27F (forward primer) and 1492R (reverse primer) were used, which were purchased from Pishgam company (Tehran, Iran). After confirming the single band, the PCR products were sequenced by Bioneer company (Tehran, Iran). The obtained sequences were analyzed through BLASTN online program. Finally, the phylogenetic tree was draw by MEGA7 software to determine the genetic similarity of the obtained isolates.

\section{Results}

Measurement of LABS degradation in control solution (non-inoculation)

The concentration of LABS in the control solution (non-inoculation) was measured on the first day according to the amount of light absorption with one mg of LABS added to the control sample. This amount of LABS decreased to $0.994 \mathrm{mg} / \mathrm{L}$ after the eighth biodegradation period, which is shown in Table. 1.

These results indicated that the concentration of LABS in the control solution did not decrease due to the absence of any microorganisms in the culture medium, which was not degradable and a very small difference (0.006) $\mathrm{mg} / \mathrm{L}$ is probably due to the error of the experiment and the device. (Fig. 1).

Table 1. Concentration and amount of LABS light absorption in the control sample.

\begin{tabular}{|lll|}
\hline Time & Absorption & LABS(mg/lit) \\
\hline 1st day & 0.335 & 1 \\
\hline 8th day & 0.332 & 0.994 \\
\hline
\end{tabular}

Measurement of degradation of LABS concentration by Bacillus licheniformis based on time

LABS concentration on the first and eighth day after biodegradation in $\mathrm{mg} / \mathrm{ml}$ was measured by Bacillus licheniformis, and showed that LABS concentration from 0.935 , on the first day, to 0.164 on the eighth day decreased, indicating a significant reduction in LABS by Bacillus licheniformis.

By comparing the concentration of LABS before and after the period of biodegradation, it is concluded that this bacterium (superior strain) has the ability to decompose and degrade LABS, and the degradation rate of this substance has reached 0.086 percent, which in comparison with the degradation rate was increased by other bacteria, which degraded approximately $0.087 \%$ of the available LABS during the 8day biodegradation period.

Figure $2(a, b)$ shows the decrease in LABS concentration and the percentage of LABS degradation by Bacillus licheniformis. 
Using a pH meter containing solution (LABS) and bacteria, it was adjusted to $\mathrm{pH} 5,7$ and 9 using 1 Normal $\mathrm{HCl}$ and $\mathrm{NaOH}$, and based on this, it was observed that the maximum degradation efficiency of LABS was at $\mathrm{pH} 7$. Nearly $87 \%$ of LABS was degraded at this neutral $\mathrm{pH}$.

The effect of temperature on LABS dagradation rate

Based on the results of this study, the best conditions for the growth of Bacillus licheniformis and degradation of $86 \%$ LABS were at $35^{\circ} \mathrm{C}$.

Based on the results of this study, the best conditions for degrading the maximum concentration of LABS in the wastewater effluent of car washes is $\mathrm{pH} 7$ and a temperature of $30^{\circ} \mathrm{C}$ and a duration of 8 days of biodegradability, using Bacillus licheniformis strain. Wastewater treatment from car wash effluents can help their biodegradation.

Macroscopic, microscopic and biochemical analyses

Based on our observations, the appearance of the colonies was rough $(\mathrm{R})$, and the gram staining showed spore gram-positive bacilli. The biochemical tests were positive for lecitinase and citrate; however, the bacteria did not grow in anaerobic conditions.

Molecular identification

Based on the results of BLASTN analysis, the isolated bacteria had the most similarity with Bacillus licheniformis. The phylogenetic tree based on the neighbor-joining method was illustrated in Fig. 3. The sequence was finally submitted to to GenBank (Accession number: SUB10326894 U-27F OK036806).

\section{Discussion}

The phenomenon of biodegradation by bacteria can be studied when these microorganisms are exposed to the substance (LABS) and may have different effects(Shuo 1992). In this case, the bacterium can first attack the products that conform to its enzyme system and then break down other substances using adaptive enzymes. If the bacterium cannot adapt to the environment, the Dioxy phenomenon occurs, meaning that the growth of the bacterium is reduced or stopped, and after a certain period of time, when the bacterium acquires the active enzyme, it continues to grow.

In this study, two 72-hour periods have been considered as primary and secondary compatibility periods for adapting bacteria to MSM medium with linear alkyl benzene sulfonate so that bacteria can adapt their physiological and enzymatic conditions with the new carbon source. The same LABS present in the growth medium are adapted and during two compatibility periods can obtain the enzymes needed to break down this substance.

According to the results of the present study, the rate of LABS degradation in the control solution, which is non-inoculated, was very small and no significant reduction in surfactant was observed. 
Horvarth et al. showed that Bacillus species could degrade alkyl benzene sulfonate by strong enzymatic mechanisms. The results of the present study showed that the rate of LABS degradation by Bacillus firmus bacteria after 8 days of exposure to alkyl benzene sulfonates is $68 \%$. Incubation day degraded $70 \%$ of LABS. This researcher also showed that the method of breaking the benzene ring in LABS by the oxygenase reaction is done by adding an oxygen molecule and producing catechol, which is converted to dihydroxy cyclohexadine by ortho and meta-generalization and then to the catech form by dioxygenase enzymes. Be converted. The present study confirms the ability of Bacillus licheniformis to degrade LABS and the use of this bacterium in the biodegradation of alkyl benzene sulfonates by about $68 \%$.

The results of this study show that the rate of LABS dagradation by Bacillus licheniformis bacteria after 8 days of biodegradation period is $86 \%$, which is the highest percentage of LABS degradation compared to other bacteria.

The present study also showed that this high biodegradation efficiency by Bacillus licheniformis bacterium up to $86 \%$ that is a gram-positive and rod-shaped bacteria, and normally present in nature, can decompose LABS well under aerobic conditions. Based on these results, this bacterium can be used in the wastewater treatment plants of detergent factories and car wash effluents for aerobic treatment system (activated sludge) to decompose the effluent from LABS to reduce the environmental damage due to the entry of these materials into the environment.

In this study, bacilli could be considered as degrading bacteria, but of course, research on other bacteria has been done by researchers. It has been shown that Arthrobacteria, Pseudomonas, Citrobacteria and Nocardia can use surfactants as carbon sources in liquid media containing detergents, as shown by measuring turbidity in liquid media. Biodegradation of surfactants, including LABS, by plasmidcontaining bacteria has also been shown.

\section{Conclusion}

In general, according to the results, Bacillus licheniformis can be used to degrade LABS and its degradation in wastewater treatment systems of car wash effluents and in detergent factories whose effluents are based on alkyl benzene sulfonates. In this way, the treatment process can be accelerated so that the effluent flow of car washes and sewage that flows into rivers and agricultural lands has less LABS residue and environmental pollution is significantly reduced.

\section{Declarations}

\section{Funding}

This study was supported financially by Dana Gene Pajoohan Karmania Company, Kerman, Iran.

\section{Conflicts of interest/Competing interests}


None

\section{Availability of data and material}

The data that support the findings of this study are available from the corresponding author, upon reasonable request

\section{Ethics approval}

'Not applicable'

\section{Consent to participate}

'Not applicable'

\section{Consent for publication}

'Not applicable'

\section{Code availability}

'Not applicable'

\section{Acknowledgments}

We would like to acknowledge Dana Gene Pajoohan Karmania Company, Kerman, Iran.

\section{References}

1. Cota-Sánchez JH, Remarchuk K, Ubayasena K (2006) Ready-to-use DNA extracted with a CTAB method adapted for herbarium specimens and mucilaginous plant tissue Plant Mol Biol Rep 24:161

2. Ghebremichael KA (2004) Moringa seed and pumice as alternative natural materials for drinking water treatment. Mark och vatten

3. Kahl S, Kleinsteuber S, Nivala J, van Afferden M, Reemtsma T (2018) Emerging biodegradation of the previously persistent artificial sweetener acesulfame in biological wastewater treatment Env sci \& tech 52:2717-2725

4. Rapaport R, Eckhoff W (1990) Monitoring linear alkyl benzene sulfonate in the environment: 19731986 Environmental Toxicology and Chemistry: An Int J 9:1245-1257

5. Shuo ZWZ (1992) Microbiol Degradation of Detergent Linear Alkybenzene Sulfonate (LABS)[J] Shanghai Environmental Sciences 2

6. Singer AC, Crowley DE, Thompson IP (2003) Secondary plant metabolites in phytoremediation and biotransformation Trend in Biotech 21:123-130 
7. Steber J, Berger H (1995) Biodegradability of anionic surfactants. In: Biodegradability of surfactants. Springer, pp 134-182

8. Suresh A, Abraham J (2019) An Overview on the Microbial Degradation of Linear Alkylbenzene Sulfonate (LAS) Surfactants Phyto and Rhizo Remed:301-313

9. Takeda K, Andoh Y, Shinoda W, Okazaki S (2019) Molecular behavior of linear alkylbenzene sulfonate in hydrated crystal, tilted gel, and liquid crystal phases studied by molecular dynamics simulation Langmuir 35:10877-10884

10. Wang Y, Zhang Y, Wang J, Meng L (2009) Effects of volatile fatty acid concentrations on methane yield and methanogenic bacteria Biomass and bioenergy 33:848-853

11. Wu M et al. (2020) Membrane fouling caused by biological foams in a submerged membrane bioreactor: Mechanism insights Water Research 181:115932

12. Yangxin Y, Jin Z, Bayly AE (2008) Development of surfactants and builders in detergent formulations Chinese $J$ of Chem Eng 16:517-527

\section{Figures}

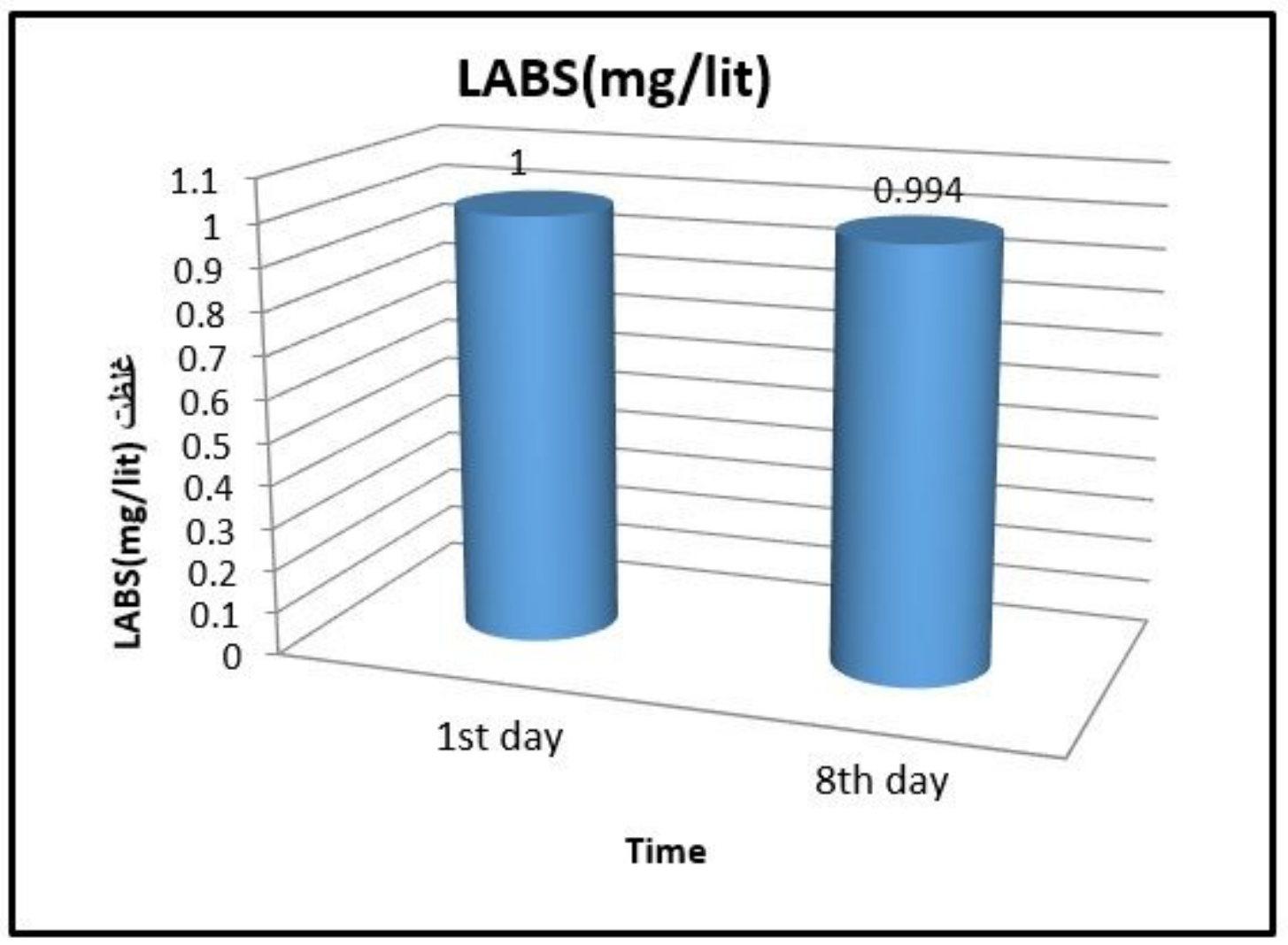

Figure 1

LABS concentration in the control sample (non-inoculation). 




Figure 2

Effect of $\mathrm{pH}$ on LABS degradation rate. 


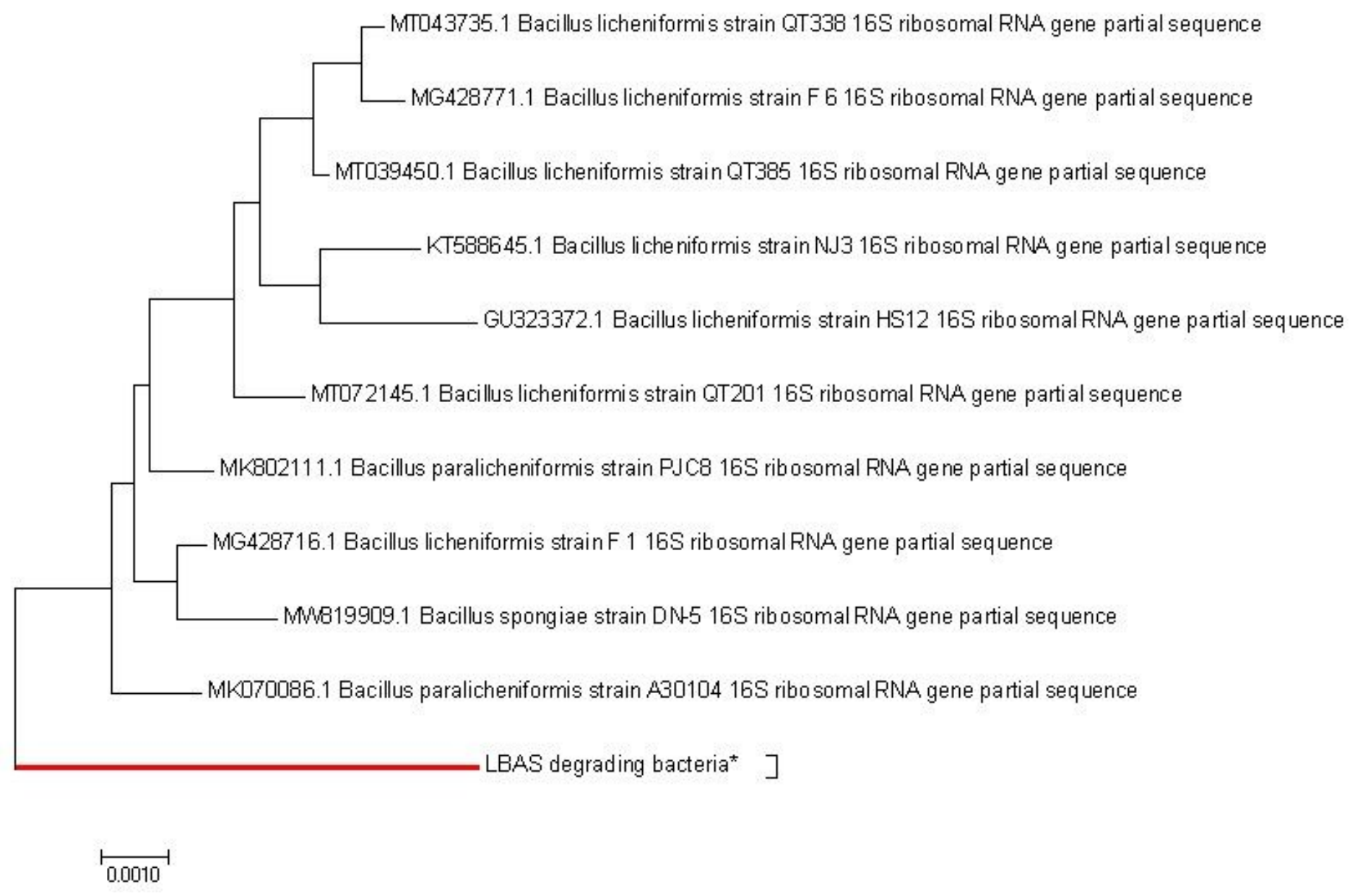

\section{Figure 3}

A phylogenetic tree of the isolated bacteria. 